\title{
Increasing Performance of the Two-Role Work Strategy: A Study of the International College Hotel and Training Center in Thailand
}

\author{
Nate-tra Dhevabanchachai ${ }^{1} \&$ Walanchalee Wattanacharoensil ${ }^{1}$ \\ ${ }^{1}$ Mahidol University International College, Thailand \\ Correspondence: Walanchalee Wattanacharoensil, Tourism and Hospitality Management Division, Mahidol \\ University International College, 73170 Nakhon Pathom, Thailand. E-mail: walanchale.wat@mahidol.ac.th
}

Received: September 27, 2013

doi: $10.5539 /$ ies.v6n12p37
Accepted: October 28, 2013 Online Published: November 27, 2013

URL: http://dx.doi.org/10.5539/ies.v6n12p37

\begin{abstract}
This research paper aims to identify the factors that will increase the performance and professionalism of the associates by using the study of the Salaya Pavilion Hotel Training Center (SPH) in Thailand as a case sample. In the study, staffs with two roles, called associates, were assessed for their job performance and motivation. Employing qualitative methodology, the assessment of associate performance was conducted with the three key stakeholders: hotel guests, intern students, and the General Manager. Furthermore, the semi-structural in-depth interviews were conducted with the associates via content analysis to reveal how they perceive their current roles and identify their motivation factors to conduct and fulfill the role effectively, by using Herzberg motivation theory as a guideline. The finding indicates that all the motivation factors of Herzberg were fulfilled in SPH. However, other important elements were found to motivate associates. Pride, which is regarded as an intrinsic factor; and the challenges from working with Generation Y students, which is an extrinsic factor, have pushed associates to strive for better performance, even though certain shortfalls remain encountered. Strategies addressing the shortfalls of performance based on the findings are proposed in the recommendation. The contributions of this study can provide insights to other hotel training centers that share similar conditions to SPH.
\end{abstract}

Keywords: hotel training, two-role duty, motivation, Thailand

\section{Background Information}

Salaya Pavilion Hotel and Training Center (SPH), Salaya, Nakhon Pathom province, Thailand, opened in 1994. It is a hotel training center managed by Mahidol University International College (MUIC), and SPH provides a compulsory internship (Internship I) for MUIC students in the hospitality and tourism program. Each year, SPH accepts approximately 120 interns over a period of three terms: January to March, April to June, and October to December. At the same time, SPH also acts as a source of income and provides hotel service to the public throughout the year. This role combination strategy has put SPH staff into two professional roles: that of a hotel employee, responsible for providing service to customers; and that of a trainer, responsible for training interns. Staffs who work in this two-role capacity are known as "associates". To achieve the SPH organizational vision and strategy, $80 \%$ of the associates, or 46 out of 60 staff, must perform the two-role duty at all times, apart from the period between July and mid-September. This position is considered highly significant for SPH, because associates have direct responsibilities toward customers and interns.

This associate role is unique compared with many well-known universities and colleges in Thailand. The students of the tourism and hospitality program at MUIC are obliged to conduct their Internship I at SPH, whereas students from other tourism and hospitality programs at other universities are allowed to freely choose any service-related organization to do their internship. For MUIC, Internship I at SPH is regarded as a core strategic training opportunity and creates a competitive advantage to the program.

Considering this dual role, additional demands are placed on an SPH associate. On first notion, an associate must be a professional trainer, because students must undergo a training series that involves the front office, housekeeping, food and beverage, and kitchen departments. Training in each department lasts three weeks on rotation and the totality of the internship duration is on a three-month period. SPH requires its associates to utilize their strong foundation and fundamental knowledge, skills and abilities, and most importantly, have the right attitude and professionalism toward students so that they become successful hoteliers. On the second notion, 
the other significant role of an associate is to provide high quality service to customers of the hotel. By positioning itself as a four-star hotel in Nakhon Pathom province, SPH attracts guests who come to visit the city as well as guests of the university, both Thais and foreign nationals. An associate must conduct their work as if they were a normal hotel staff employee whose performance and efficiency relate directly to positive customer experience and satisfaction.

\section{Problem Identification}

The strategic human resource management of SPH is unlike any other profit-making hotel or training center of other tourism and hospitality institutes in Thailand. SPH employs those who are not only passionate in their service, but also a desire to teach and train. Due to MUIC and SPH's location, which are further away from the business area and the capital city, SPH is characterized by a limitation to attract fully qualified candidates for associate vacancies. The existing associates were hired for their highly positive attitude, willingness to develop, and their tendency to commit long-term to the job, which is important because the skill consistency in the internship training is one of the crucial factors that SPH considered. However, this has unavoidably affected certain associate skill levels, in particular English language proficiency and career motivation.

SPH have employed various means to increase staff performance and efficiency to ensure that associates would carry out both roles in a professional way and with motivation. Approaches that SPH employs to improve staff performance include the use of various mechanisms, both direct and indirect financial aspects. Direct financial benefits include the use of decent wages, salaries, and commissions. Indirect financial benefits include social welfare, health care, paid vacation, and aspects to improve job performance, such as increasing the skill and task varieties, giving job autonomy, giving feedback, and creating a positive job environment.

Despite the aforementioned strategies and approaches, occasional feedbacks from intern students on a shortfall of performance and associate enthusiasm have been addressed. This is also supported by certain on-site observations from the SPH's General Manager (GM). This creates doubts and concerns, resulting in the GM seeking the real reasons of this phenomenon. On one hand, the GM wondered if the motivation level of the associates have decreased, and investigated the key success factors that push associates to be motivated within the two-job role.

\section{Research Objective and Questions}

The purpose of this research study is twofold: first, to find out whether the motivation factor causes associates underperform as regards the two-role duty, and second, to address the success factors that can drive SPH's associates to perform their two-role duty effectively, and create higher job motivation and professionalism within this role. Therefore, the research study raises the research sub-questions as follows:

Is motivation a key reason that relates with the associates' performance? If so, does the motivation theory proposed by Herzberg remain effective and appropriate for this phenomenon of the role of associate at SPH?

What are the effective approaches that lead to highly professional and motivated associates?

\section{Literature Review}

\subsection{Motivation}

According to Pinder (1998), the concept of motivation is difficult to clearly define, as "there are many philosophical orientations towards the nature of human beings and about what can be known about people" (Pinder, 1998; Meyer, Becker, \& Vandenberghe, 2004). The theory of human motivation has long been discussed since the ancient Greeks explored the concept of hedonism (Steers, Mowday, \& Shapiro, 2004), meaning that an individual seeks pleasure and avoids pain. The idea of motivation was developed and shifted from philosophical study into the field of psychology around the end of the nineteenth century. This became the starting ground of many behavioral studies in motivation such as "instinct theories" (behavior results from instinct and can lead to motivation), and "drive theories" (decisions concerning present or future behaviors are largely influenced by the consequences of reward associated with past behavior). Thorndike (1911) refers to drive theory as the law of effect, meaning "past actions that led to positive outcomes would tend to be repeated, whereas past actions that led to negative outcomes would tend to diminish" (Steers et al., 2004, p. 380). On the other hand, Hull (1943) suggests that motivation is largely defined by drive multiplied by habit (drive $\mathrm{x}$ habit). Through these developments of thought, drive theories grounded the basic concept and became one of the influential vehicles toward the understanding of work motivation (Steers et al., 2004).

The exploration of motivation literatures has shown that there are many theories leading to work motivation, which can be mainly grouped into "need theories" and "process theories" (Lundberg, Gudmundson, \& 
Andersson, 2009; Steers et al., 2004). Need theories concentrate on the emotional aspect of motivation and are based on the assumption that people's needs provide the force which directs action toward fulfilment of these needs (Lundberg et al., 2009; Pinder, 1998). Before need theories became a vehicle of the development in work motivation, the study of human motivation by Maslow (1943) had paved the way for a better understanding of the hierarchy of human needs. Further study by McClelland (1971), however, put more in-depth focus on the motivational potency and clearly defined needs in terms of achievement, affiliation, power, and autonomy (Steers et al., 2004). In contrast to Maslow's hierarchy of needs, McClelland believed that at any given time, individuals possess needs that serve to motivate behavior when activated. Shortly afterwards, the study on need theories by Herzberg shifted the focus of motivation from individual fulfilment to the scope of work activities relating to motivation and performance. Herzberg's work (Herzberg, Mausner, \& Snyderman, 1959) further led to the development of studies in job design and job enrichment (Steers, 2004).

On the other hand, process theories put emphasis on the cognitive process, view work motivation from causal relationships, and try to understand the thought processes that people go through in determining how to behave in the workplace (Steers et al., 2004). In general, when compared with need theories, process theories are seen to look at motivation from a more dynamic perspective (Meyer et al., 2004; Steers et al., 2004). Steers et al. (2004) illustrate the ramifications of work motivation theories which are based on the process theories as follows: "expectancy theory" (the attractiveness of a particular task and energy invested in it will depend a great deal on the accomplishment that an employee believes it leads to valued outcome (Tolman, 1959)), "equity theory" (underpayment and overpayment can influence how employees respond both cognitively and behaviorally to the perceived unfairness in the work place (Weick, Bougon, \& Maruyama, 1976)), "goal-setting theory" (the simple act of specifying targets for behavior-enhanced task performance (Lock \& Latham, 1990)), and "social-cognitive theory" (self-confidence lies at the heart of an individual's incentive to proactively act (Bandura, 1997)).

In the present stage, although the concept of work motivation has still been viewed as not rigid and complex (Lundberg et al., 2009; Steers et al., 2004), the definition of work motivation by Pinder (1998) is still widely referred to, as it provides a clear definition that captures different theoretical perspectives:

Work motivation is a set of energetic forces that originate both within as well as beyond an individual's being, to initiate work-related behaviour, and to determine its form, direction, intensity, and duration (cited in Meyer et al., 2004).

From this definition, Meyer, Becker, and Vandenberghe derive two important points: 1) motivation is identified as an energizing force which induces action in employees, and 2) this force has implications for the form, direction, intensity, and duration of behavior.

\subsection{Work Motivation in the Hotel Industry}

A few theories have been employed in the hotel industry to gain employees' motivation. For instance, expectancy theory which is originally developed by Vroom (1964) is a theory which explains the process that individuals use to make decisions on various behavioral alternatives. Expectancy theory is a theory of the process of motivation where it defines how motivation comes about (Abadi, Jalilvand, Sharif, Salimi, \& Khanzadeh, 2011). Despite its provision in providing a general framework for assessing employee behavior in learning, decision making, attitude formation, and motivation (Chen \& Lou, 2002 as cited in Chiang \& Jang, 2008), the theory is criticized of lacking strong theoretical framework and validity of components within the model. Furthermore, a search of the literature indicates that a number of studies on work motivation in the hotel industry have adopted Herzberg's theory (Chitiris, 1988; Lundberg et al., 2009; Sledge, Miles, \& Coppage, 2008; Wong, Siu, \& Tsang, 1999), as which addresses both intrinsic and extrinsic factors for motivation. Herzberg's two-factor theory bases its idea on the "need theories" and suggests that humans have two different sets of needs and that the factors causing job satisfaction (presumably motivation) are different from those causing job dissatisfaction (Lundberg et al., 2009; Wong et al., 1999). The key proposal of this theory is that certain job factors (so-called "motivators") such as achievement, recognition, growth, and advancement lead to job satisfaction. On the other hand, the other job factors (so-called "hygiene factors"), if not present, will lead to job dissatisfaction. The latter elements include work conditions, salary, relationship with boss, and relationship with peers. The fundamental idea of the two-factor theory is shown in Table 1 below.

Despite arguments and criticisms that question some of the factor components in the theory (Parson \& Broadbride, 2006; Lundberg et al., 2009), most of the literature on motivation within the hotel industry has shown support for this model. For example, the study by Lundberg et al. (2009) on the seasonal workers in ski-resort in northwest Sweden confirmed that the work motivation is grounded in the satisfaction of "higher needs" or "self fulfilment needs" (Pinder, 1998) and not in more mundane needs such as wage level. The study 
by Wong et al. (1999) on employees of the Hong Kong Hotel supported Herzberg's theory that the provision of hygiene factors prevents employees from being dissatisfied with their jobs, yet does not guarantee actual satisfaction. The study by Sledge et al. (2008) on the motivation and job satisfaction amongst hotel workers in Brazil partially supports the two-factor theory, as the authors suggest that cultural factors also influence the degree of job satisfaction and that culture helps explain why the original motivators or hygiene factors did not affect some employees.

Table 1. Two-factor theory by Herzberg (1966)

\begin{tabular}{cc}
\hline Motivators: Elements leading to job satisfaction & Hygiene factors: Elements leading to job dissatisfaction \\
\hline Achievement & Policy and administration \\
Recognition & Supervision/managerial relationship \\
Tasks & Working conditions \\
Responsibility & Pay \\
Advancement & Co-worker relationships \\
Personal growth & Status \\
& Security \\
\hline
\end{tabular}

Although its original concept is based on need theories, various components in this two-factor theory, such as pay (hygiene factor), achievement, and recognition (motivators) are the components which, when deeply scrutinized, can provide better insight and a good support for process theories as in the equity theory, goal-setting theory, and social-cognitive theory, respectively. Hence, Herzberg's theory is regarded as appropriate for use as a guideline on motivation in this research.

\subsection{SPH and Challenges on the Two-Role-Facet}

Having two responsibilities can place pressure on an individual as well as on associates of SPH. Operating with 43 rooms, SPH shares a similar Human Resource Management (HRM) strategy as a small- to medium-scale hotel in terms of recruiting, training, and motivating people. Smaller size hotels usually have to employ staff who have limited qualifications (Ahmad, Solnet, \& Scott, 2010; Young-Thelin et al., 2012) compared with the top hotel brands. However, in contrast to the small- to medium-scale hotels, which experience high staff turnover, SPH turnover rate is considered not significant due to the job security that the organization provides along with the high reputation of its parent institute.

With the unique nature of the associate role in SPH, however, not much of the literature deals with the conflict between the dual roles of trainer and hotel employee. Hence, the challenges and constraints for a full-time hotel staff member who is at the same time a full-time trainer have not yet been studied, especially regarding the phenomenon where staff have to perform these two roles for three-quarters of the year. Despite the lack of literature on the conflict between the roles of trainer and hotel employee, research articles exist that refer to the inter-role challenge in other areas. These research papers demonstrate that individuals have dispositional tendencies to experience both inter-role conflict and inter-role facilitation (Greenhaus \& Beutell, 1985; Hecht \& McCarthy, 2010). According to Greenhaus and Beutell (1985, p. 77), inter-role conflict is pressure "from [two] domains which are mutually incompatible in some respect". On the other hand, the inter-role facilitation is defined as a situation where one role makes it easier to participate in the second role (Frone, 2003; Hecht \& McCarthy, 2010). This idea derives from the thought that participating in one role increases the resources that a person has to participate in another role. In fact, most studies about two-role conflict are found in the field of psychology and are focused on two completely different roles such as employee-family or student-employee scopes. Hecht and McCarthy (2010) state that role conflict has developed from the resource drain model, which posits that individuals have limited resources that are no longer available for other role(s) once they have been expended. When the focus is placed on the hotel industry, most studies on two-role conflict mainly investigate the correlation between work and family life, emotional exhaustion, or intrinsic motivation (Karatepe \& Uludag, 2007). It has been observed by the SPH's GM that associates could suffer from emotional exhaustion, especially since the role requires professionalism at all times, both in the front and back stages of operation. This might create job de-motivation and the shortfall of performance. This notion will be looked into as part of the 
consideration toward promoting associates' motivation levels.

\section{Methodology}

This research employs the qualitative research methodology, the philosophy of which is appropriated for investigating issues that are dynamic and contemporary (Perry, 2001; Dul \& Hak, 2008; Ahmad et al., 2010). In this study, a combination of qualitative approaches and survey data collection will be carried out at SPH in Nakhon Pathom, Thailand via the primary data source. The semi-structured interview, a technique that ensures there is sufficient flexibility to enable respondents to respond freely and fulfill certain requirements for the study (Drever, 1995; Cohen \& Crabtree, 2006), is also employed in the study.

The stakeholders who were selected for interview were classified into three main groups: 1) hotel customers and internship students; 2) the GM of the SPH, and; 3) the staff members who hold an associate role. Ten hotel guests and ten intern students were randomly selected for the interview, because these interviewees are direct customers of the associate role. Therefore, their opinions and perceptions regarding the efficiency and satisfaction toward associates are important. The hotel guests were approached randomly and were interviewed on the last day of their stay at the SPH as a general record, which helps SPH service improvement. Similarly, two intern students remain under operation and those who already finished their internship period were randomly selected for interview on associate performance during and after the internship period.

Furthermore, the GM of SPH is among the interviewees to seek management perception on associate job performance. This provided an improved understanding of the present human resources strategy on training and motivation employed at SPH. This process was conducted via an in-depth interview. Third, ten associates from all four departments were interviewed to elicit their perception toward the two-role duty, of which they had already been informed since the recruiting process, as well as the benefits and constraints of the role and the perspective behind their job motivation.

In total, ten hotel customers, ten internship students, ten associates, and the GM were interviewed. The number of interviewees is perceived as adequate for this research; in all of the interviews, apart from that with the GM, data saturation was achieved at the $6^{\text {th }}$ or $7^{\text {th }}$ interviewee. Considering that the interview was conducted in Thailand and the GM of the SPH is one of the researchers in the team, the HR assistant was assigned the responsibility of conducting the interview after being briefed by the researchers, in order to avoid bias. All interviews were conducted in Thai and recorded on an electronic device. Data translation was initially done by the first researcher and was cross-checked by the second researcher for reliability. Details of the associates selected for the interview are provided in Table 2.

Additional data sources were also derived from the existing SPH customer surveys and internship feedback conducted in 2012 to triangulate associate performance. The total number of customer surveys is 25,044 responses, and 120 responses for intern survey, which is the number of student interns per year. Data triangulation helps researchers reduce bias on the collected data, promotes content validity, and provides a better understanding on associate performance.

The stakeholder interviews were followed by data coding and content analysis. The two-factor theory by Herzberg was employed in this study as the main benchmark for motivation theory because it represents clear attributes of motivation factors, as outlined in Table 1. These factors have also been pinpointed in other studies (Wong et al., 1999; Sledge et al., 2008; Lundberg et al., 2009) to help improve employee motivation, leading to job satisfaction and better performance in the workplace. 
Table 2. Details of associates as interviewees

\begin{tabular}{ccc}
\hline Associate role & Age & Years/Months working as an associate \\
\hline Housekeeping Manager & 43 & 8 years 9 months \\
Director of Sales and Marketing & 33 & 7 years 4 months \\
Sales and Marketing Manager & 37 & 5 years 8 months \\
Front Office Manager & 39 & 6 years 4 months \\
Front Office Assistant Manager & 38 & 7 years 4 months \\
Assistant Food and Beverage Manager & 50 & 9 years 9 months \\
Front Office Manager & 40 & 9 years 4 months \\
Front Office Supervisor & 37 & 8 years \\
Receptionist 1 & 31 & 5 years \\
Receptionist 2 & 30 & 4 years 3 months \\
Average & $\mathbf{3 7 . 8}$ & 7 years 3 months
\end{tabular}

\section{Research Findings}

\subsection{Feedback from Customers}

\subsubsection{Hotel Customers}

The first stakeholder category selected for interview was the hotel customers. In general, overall guest satisfaction was very high, and considering that guests understand that SPH is a hotel training center, they tend to view the service performance positively and do not feel that SPH is lacking service quality when they see trainers with students during service. The interview results on associates are very positive. Nine out of ten guests provided comments indicating high service quality, with all staff welcoming guests and being very hospitable. The interview data are aligned with the results of the hotel surveys gathered in 2012. According to the surveys, out of the 25,044 hotel guests, the average satisfaction score is 9.02 out of 10, with a standard deviation of 0.689 . This average satisfaction score is derived from guests staying in the hotel and also guests use function facilities. Interviews with hotel guests also confirm the positive performance of associates. These results demonstrate that SPH associates, having the industry background and technical knowledge, have performed their role as hotel staff with professionalism to a satisfactory level. The policy on service charge is important in improving performance. A clear establishment of SPH hotel as a training center makes hotel guests aware of this fact. This could lead to guests' higher levels of tolerance and lower levels of expectation, allowing more room for understanding and forgiveness toward SPH's service quality. The result of the hotel survey and examples of customer interviews are shown in Table 3. 
Table 3. Results from hotel guests on service performance

\begin{tabular}{ccc}
\hline Question & \multicolumn{2}{c}{ Result } \\
\hline Survey from hotel guests and & & Standard Deviation \\
\cline { 2 - 3 } guests using functions and & & \\
facilities: & 9.02 & 0.689 \\
How would you rate the general & & \\
service of our staff & & \\
$\mathbf{1}$ (awful)-10 (excellent) & & \\
\hline
\end{tabular}

Salaya Pavilion's service could be the sample hotel for many 5-star hotels and it could be called a professional hotel that people may like to come to visit.

Interview samples

How do you feel about SPH's service performance?
(Guest 3)

We were very happy with your service and we wish to give a tip to be shared among young students who made our stay here a happy one.

(Guest 5)

We received excellent service from everyone. Thank you. (Guest 8) Staff and students are very nice, kind and very hospitable.

(Guest 2)

\subsubsection{Intern Students}

On the other hand, feedback from intern students is also derived from two sources, the SPH survey on interns and the interview results. Regarding the survey results of 120 students, the average learning satisfaction results are above 8.5 out of 10, apart from English communication, which received the lowest average satisfaction score of 7.67. All questions show the low figures of standard deviation, demonstrating that the data do not have much variation from the average score. The results are presented in Table 4.

In order to further understand and examine whether certain hidden messages could not be derived from the survey, intern interviews were conducted. The results from the interviews show both positive and constructive feedback toward the performance of associates. On a positive note, students have a positive impression toward training by associates and feel that they learn a lot of new knowledge that will be useful for their future career. On the other hand, when being asked if they believe that trainers are motivated to teach, 7 out of 10 students commented on the lack of professionalism of trainers:

"Sometimes, some of them (the associates) take things for granted. They are slacking, sitting around, talking and let students do the work or disappear without informing students where they are." (Intern 2) 
"Some of them do not like to confront the students who are not afraid to argue with the trainers. Trainers seem to lack confidence in teaching and it affects the quality of their training." (Intern 3)

One of the key roles of a trainer is the ability to provide feedback to students. However, when asked about the effectiveness of the feedback given by associates, interns addressed the shortfall of ability of associates:

"No individual feedback was given to us; mostly it was a group feedback. It would be good if I receive individual comments from the trainers." (Intern 7)

"Some trainers did not tell students what is right or wrong, we don't know why. But later students knew what we did was not right. Students prefer that the trainers give students feedback right away." (Intern 3)

"It would be good to get feedback from time to time, let's say weekly. In fact, instant feedback is better, but I understand that sometimes trainers might have no time and energy to do so." (Intern 2)

One of the interesting comments made by interns toward associate performance is regarding the level of confidence due to the limitation of associates' international exposure, reflecting upon their language and confidence as follows:

\begin{abstract}
"Some trainers do not know how to approach us, they are afraid of us, we feel. Maybe they feel we are educated, as most of us do have international exposure, and therefore they do not want to say anything much. What I personally have seen is some students say something very strong to the trainers, and the trainers seem to close themselves and do not want to interact much with trainees. I think we should have ice-breaking between trainers and trainees. This also links to some behaviors and disciplines that trainees should not do but the trainers would not like to emphasize to the trainees. I think this will affect the quality of the trainees and the training as a whole." (Intern 1)
\end{abstract}

The similar interview result was re-addressed by three more intern students, and this yielded an interesting notion that shows an implication toward the job performance of associates. Based on the interviews, the "power of social status" was implicitly mentioned. The gap of "international exposure" reflected the gap of social status between interns and associates, affecting to the shortfall of effective training. Despite having satisfactory technical hotel skills, associates have limited international experience, leading to less international exposure and limited English language proficiency. On the contrary, interns tend to have stronger international exposure due to the advantage of wealth and social status. Thus, they expect high professional training, especially with an acceptable level of English usage as a medium of communication. These issues have created gaps between intern expectations and associate performance, while simultaneously creating pressure and the feeling of challenge for associates, resulting in lower levels of confidence in teaching and providing constructive feedback to interns. 
Table 4. Satisfaction result derived from the internship survey to 120 intern students in 2012

\begin{tabular}{|c|c|c|c|}
\hline No. & Questions & Average Satisfaction Score & $\begin{array}{l}\text { Standard } \\
\text { Deviation }\end{array}$ \\
\hline 1 & $\begin{array}{l}\text { How best of your overall learning experience at } \\
\text { Salaya pavilion for total of } 3 \text { month-internship? }\end{array}$ & 9.18 & 0.591 \\
\hline 2 & $\begin{array}{l}\text { After receiving basic knowledge about hotel } \\
\text { operation from your academic program, did the } \\
\text { training curriculum you received at Salaya } \\
\text { Pavilion over the period of } 3 \text { months effectively help } \\
\text { you to understand the fundamentals of hotel } \\
\text { operation? }\end{array}$ & 9.17 & 0.597 \\
\hline 3 & $\begin{array}{l}\text { How strong is the professionalism level of the } \\
\text { trainers and staff at Salaya Pavilion, in your } \\
\text { opinion? }\end{array}$ & 8.72 & 0.652 \\
\hline 4 & $\begin{array}{l}\text { How well does each trainer support your learning } \\
\text { and working at SPH? }\end{array}$ & 9.07 & 0.642 \\
\hline 5 & $\begin{array}{l}\text { How satisfied are you regarding the English } \\
\text { communication of the trainers? }\end{array}$ & 7.67 & 0.582 \\
\hline 6 & $\begin{array}{l}\text { As the success of training is combined with many } \\
\text { different factors, how would you rate your learning } \\
\text { success based on the quality of the training } \\
\text { curriculum, trainers, facilities, and equipment. }\end{array}$ & 8.91 & 0.690 \\
\hline 7 & $\begin{array}{l}\text { Finally, spending your } 3 \text { months at SPH, please rate } \\
\text { the following: }\end{array}$ & & \\
\hline & $\begin{array}{l}7.1 \text { I have gained more knowledge about hotel } \\
\text { operation }\end{array}$ & 9.36 & 0.444 \\
\hline & 7.2 I have gained more skills in working as a hotelier & 9.33 & 0.459 \\
\hline & $\begin{array}{l}7.3 \text { I have changed my attitude to be a more } \\
\text { disciplined and professional person }\end{array}$ & 9.32 & 0.362 \\
\hline
\end{tabular}

\subsection{Feedback from the General Manager}

The GM of SPH was interviewed to obtain her perception toward associate performance and efficiency. From the in-depth interview, three main areas were observed by the GM as the key concerns. The first concern falls on a trainer's self-learning ability. In the view of the GM, most of the trainers require in-depth knowledge and skills, together with regular updates about their field of work. In the GM's view, trainers should be responsible for their own self-development and not simply wait for the organization to provide input:

"At SPH, the products are very simple, therefore it does not require a sophisticated teaching. Instead, it demands a great deal of valuable and insightful explanation of fundamental knowledge regarding hotel operation with which students need to be grounded. Thus, as a trainer at SPH, one should be very well-rounded and have an in-depth comprehension and conception of what one teaches the students. SPH's trainers still need to work on this." 
A further concern addressed by the GM is based on a trainer's commitment in giving daily feedback to students. The GM provided her own assumption that the reason for not readily providing such feedback could come from Thai culture, which avoids confrontation. This could be a reason as to why associates do not provide interns with direct comments on the shortfalls of their performance, even though it reduces the effectiveness of the students' training. Another reason from the GM's perspective is that trainers wish to maintain good relationships with the trainees because they need to work as a team for three months. Often, trainers have to rely on trainees to fulfill heavy labor work. Thus, they do not want to provide comments that may be viewed as negative to the trainees and result in animosity.

The last point addressed by the GM was her expectation that the staff should be able to professionally balance their hotelier and trainer roles:

"In most hotels that are not training centers, staff only spend time with guests at certain moments and then, behind the scenes, they can relax. However, when SPH staff are not with guests they are with students. This is a big challenge but the staff are often encouraged by me to perceive this as a self-development stage. Therefore, the staff at SPH have to balance the way(s) that the trainer has to be with students, such as modeling discipline, professionalism, manners, and being a role model. Sometimes staff tends to slack and lack discipline as they may forget that they have to be a role-model for students. They still need to be reminded of this on a regular basis."

\subsection{Feedback by the Associates}

SPH associates were questioned in order to discern their perception on their two-role duty and to seek out the hidden motivation factors that make them feel encouraged and want to increase their job efficiency. When asked how they feel about the two-role responsibility, most trainers perceive this job as very challenging. Although associates admit that it is not easy, they feel proud of their extra role as trainer. They believe that by being with students, they can develop themselves at all times, because the environment forces them to be a good role model. Moreover, they must be very good at what they do, because they must perform well and be knowledgeable before teaching students. Comments derived from the interviews are demonstrated as follows:

"It is challenging, not easy but not too difficult. We have to be very good and deal with guests correctly, as we are the role models for students. This is good for us, as we perfect ourselves at all times and I'm proud of that. In the past, I was a receptionist, and when we didn't have guests we gossiped and talked about guests behind their backs. But here at SPH, I could not do that because I am with students. If there is anything about guests we wish to say, we can only do so with students in a professional way. At the end, the two roles are quite the same, as we care for our guests by providing the best service, but we also take care of students by providing knowledge. When we provide information to guests, it is simpler than to students, because when we give information to students, we have to explain what and why and how, hence, it is a deeper level that we have to adjust." (Associate 7)

"It is quite hard to perform two roles. We have to balance a great deal of work. We have to have high leadership, a sense of justice, and we have to make good decisions, as we have to care for both guests and students." (Associate 6)

"It is challenging in terms of finding a balance on both roles at the same time. But I feel proud of what I do and I believe I am developing myself at the same time. Not many people have such a great chance. We have to have a good teaching skill and be good role models all the time. We have to pay attention to our own professional development and we must have reasons why we do certain things as we have to teach well." (Associate 5)

When asked about what motivates associates to develop their role, various reasons were given ranging from happiness providing a service, the pleasure gained from satisfying guests, a good working environment, and management's moral support. However, to the researchers' surprise, most of the answers reflected the "nature of students" and "pride" as motivation factors to improve and develop: 
"Students are not the same so it motivates me to teach. Being a teacher is my goal. I'm proud of being a teacher. Hotel work is my revenue, being a teacher is my honor." (Associate 3)

"It is a happiness to serve guests and it is a pride to teach students who are well educated, like MUIC students. When they can do what we teach, we are very proud. I wish for them to do well or even better than us. When they get compliments, it is like our compliment too. I feel teaching students is a two-way conversation." (Associate 4)

"Students change every three weeks due to their departmental rotation, and I learn something new from every change. I feel proud also that I am helping them in their education and it is a kind of give and take knowledge between trainer and trainees." (Associate 1)

"They are GEN Y, they are not repetitive, and they give us a change in life. They are colorful. Also, teamwork of SPH is another motivation. Moreover, the GM's direction is clear. In the past, we didn't know service and we didn't know vision, what it meant, what the system was. We were unclear, but we are now very clear." (Associate 2)

As regards the question of compensation, 9 out of 10 associates mentioned that they are happy with the salary, and two further stated that they would be happy to receive extra income from training. Other factors such as the physical working conditions and environment, relationship with the team, career status, relationship with management, clear policy, and job security were also satisfactory. This strongly supports the two-factor theory proposed by Herzberg because the basic needs or hygiene factors must be fulfilled to avoid creating job dissatisfaction. However, these factors do not provide the valuable meaning when compared with the intrinsic value (called motivators in Herzberg's theory), which leads to job motivation and satisfaction.

From the interview results with associates, the two factors which were repeatedly mentioned by associates as motives improve performance are "the nature of interns" and "the feeling of job pride". Having said that, despite wanting to be effective in their role, none of the associates clarified what they must do to improve performance and the notions of training and development were not mentioned at all by any of the associates as important mechanisms for development. When this was addressed, all associates agreed that training and development are important, and when the question of what type of training associates would require, the answer was that the courses should relate to SPH's environment.

\section{Discussion and Recommendations}

The original assumption of the shortfall in associates' performance and professionalism due to the lack of motivation cannot be fully applied in this case. As the results demonstrate, SPH's associates are mostly satisfied with all attributes in Herzberg's two-factor theory of motivation. The results derived from the data collection have shown new emerging aspects. The new motivating elements of "job-pride" and the dynamic "nature of Generation-Y interns" influence associate desire to remain in the job and perform better. Hence, the real reasons for the shortfall of associate performance and professionalism could be based on other elements.

The nature of interns is found to be a job-motivation factor for associates, which can be addressed by employing the influence of social status to elaborate. Training intern students studying in a reputable institution with high international exposure makes associates simultaneously feel proud and challenged. This influences them to want to improve their performance, and consider this task as their own personal growth. Furthermore, the nature of the younger generation brings in dynamic vibes and colorful spectrum to the job, which also promotes a positive and dynamic learning environment for associates. On top of that, the meaning of the job itself fosters good attachment, but the nature of the students pushes associates to see this role as challenging and want to perform better.

The finding supports earlier study (Chiang \& Jang, 2008) that the intrinsic motivation factors are more influential than extrinsic factors for hotel employees, including in the hotel training center. Associates at SPH view pride as a dominant motivation factor to remain in and pursue the role. Pride is a new element that was not mentioned in Herzberg's two-factor theory. The term "pride" is different from the term "recognition", which is a motivator for job satisfaction mentioned by Herzberg. From the psychological perspective, pride is a positive, self-conscious emotion arising from achievements and recognitions that can be attributed to one's abilities or efforts (Lewis, 1997; Tangney, 1999; Williams \& DeSteno, 2008). Hence, pride is the self-valued outcome of a person, resulting from recognition by others. The study by Williams and DeSteno (2008) demonstrates that pride 
is an excellent candidate for a motivational role and leads to greater perseverance, as the authors state that "when feeling proud about a recognized accomplishment, an individual feels an incentive to pursue further action in that valued domain" (p. 1008). For the SPH associates, the pride of being a trainer is one of the key elements that attaches them to the role. It is the feeling of "job-pride" that gives an intrinsic motivation and deeper job satisfaction to associates, leading to long-term job commitment. However, a discrepancy of associates" action resulting from pride is found when compared with the study by Williams and DeSteno (2008), because associates continue to lack a high level of perseverance to take a self-development initiative to improve their performance within the role.

Based on the finding, in order to address the ways that can drive SPH's associates to perform their two-role duty effectively and create higher job motivation and professionalism within this role, the causes of underperformance and the recommended theories should be addressed. For the causes of underperformance, these main notions were captured from the study: 1) the lack of confidence as a trainer to provide constructive feedback for interns, 2) the lack of individual responsibility for self-development, and 3) the lack of discipline. For the first reason, although the lack of English proficiency is a factor that prevents associates from providing constructive feedback to interns, it is seen as a symptom of the lack of confidence. As a trainer, associates are given a legitimate social power (French \& Raven, 1959) to teach and train interns, yet their limited international exposure is the hidden/implicit reason leading to the underperformance. This, together with the national culture of avoiding conflict and the desire to create harmony in the work place, results in a shortfall in the professionalism of associates. Therefore, the motivation theory cannot be the only mechanism to increase the job performance of associates, since more training and development mechanisms are needed to develop their performance. The level of confidence comes with more exposure, training, and developing a culture of providing feedback. These can be enhanced within the SPH organizational culture.

Secondly, the problem of individual responsibility for self-development was mentioned by the SPH's GM. This could be improved via the application of behavioral and self-learning theories, which state that external stimuli can influence behavior (Rowe, Savigny, Lanata, \& Victora, 2005). Associates are not proactive in their self-learning, despite their desire to improve, hence the point of development still requires management initiatives to provide necessary training and instill the self-learning and development culture. More international hotel exposure and peer pressure can also be used as push mechanisms. Other beneficial attitude training, communication, and providing feedback skills can also be provided and continued until the actions turn to habits.

Furthermore, the problem of lacking discipline and acting unprofessionally requires a stricter mechanism. There might be the need to use coercive approaches (French \& Raven, 1959) to handle the misbehavior of associates. Repetitive improper acts could mean that the person is not qualified for the role and might require rotation to another job role or function. Table 5 below addresses the theories that can be integrated to increase associates' job performance. 
Table 5. Theories that can be integrated to increase associate performance

\begin{tabular}{|c|c|c|}
\hline $\begin{array}{c}\text { Relevant } \\
\text { Theory }\end{array}$ & ssumptions & Application and implementation by SPH \\
\hline $\begin{array}{l}\text { Herzberg's } \\
\text { two-factor } \\
\text { theory }\end{array}$ & $\begin{array}{l}\text { Hygiene factors, if not fulfilled, will } \\
\text { lead to job dissatisfaction, while the } \\
\text { motivator factors, if fulfilled, will lead } \\
\text { to job satisfaction (Need's theory of } \\
\text { motivation). }\end{array}$ & $\begin{array}{l}\text { Maintain the acceptable level of hygiene and } \\
\text { motivator factors provided to employees. } \\
\text { Provide challenging tasks and include the element } \\
\text { of job-pride into the associate training session. }\end{array}$ \\
\hline $\begin{array}{c}\text { Behavioral and } \\
\text { learning } \\
\text { theories } \\
\end{array}$ & $\begin{array}{l}\text { Behaviors are a result of external } \\
\text { stimuli. }\end{array}$ & $\begin{array}{l}\text { Training sessions that encourage job pride, the } \\
\text { importance of the role of associates as trainers. } \\
\text { Attitude training. Other necessary skill trainings. }\end{array}$ \\
\hline $\begin{array}{c}\text { Social } \\
\text { influence and } \\
\text { power theories }\end{array}$ & $\begin{array}{l}\text { Change occurs via the interaction and } \\
\text { influence of important people, and } \\
\text { through development of social norms. }\end{array}$ & $\begin{array}{l}\text { The interns' qualifications and nature will push } \\
\text { associates to develop and strive to improve their } \\
\text { practice. }\end{array}$ \\
\hline $\begin{array}{c}\text { Coercive } \\
\text { approaches }\end{array}$ & $\begin{array}{l}\text { Change occurs because of pressure and } \\
\text { control. }\end{array}$ & $\begin{array}{l}\text { Watch for unacceptable behavior such as } \\
\text { associates skipping work and not acting } \\
\text { professionally. If the action keeps repeating, it } \\
\text { could mean the person is not suitable for the job } \\
\text { and thus further action is required. }\end{array}$ \\
\hline
\end{tabular}

\section{Conclusion}

SPH is a unique organization that strives for excellence in the two roles it serves and has achieved a high level of satisfaction both from hotel guests and interns. However, there are certain shortfalls of performance within the role of associates that SPH must investigate as the phenomenon does not appear explicitly in the guest and intern evaluation. Through the qualitative research methodology, employing semi-structured interviews with relating stakeholders, new findings on job motivation of the associates' roles are made known and the improvement mechanism is proposed and discussed. The research results have answered the main important questions stated in the research objective. The findings of this research support Herzberg's theory that all the hygiene factors, when not being fulfilled, will lead to job dissatisfaction. However, this does not create job motivation and satisfaction, whereas the motivator factors are attributes that lead to job satisfaction. Hence, Herzberg's two-factor theory remains reliable within the hotel industry context. However, the finding represents new elements, which are the perception of "pride" toward the job and the "nature of trainees" as dominant motivators for associates to pursue for development. The research also demonstrates that the underperformance of associates is not due to, but the existence of lower levels of confidence and the lack of individual responsibility on self-development. This gives implication to SPH's management that the necessary financial and non-financial compensation for trainers must be continuously assessed, along with new findings on motivational factors.

Managerial implication and limitation:

The managerial implications of this research paper could be recommended. First, this can be a good case sample for small-scale hotels that have certain difficulties when employing the averagely qualified hotel staff with limited international exposure and lack of job motivation. Herzberg's two-factor theory can still be referred to as a good principle to avoid job dissatisfaction and create motivation. Further elements of job pride and task challenges can also be implemented, along with necessary training. This must be continuously implemented in order to turn actions into culture. This study can also be useful for other hotel training centers, both in Thailand and in the international context sharing the similar nature, in order to apply the recommended mechanism to develop staff performance.

The limitations of this research mainly originate from the timing factor. The satisfaction surveys used in this research were taken from existing ones provided by the SPH without adaptation. Thus, , they might not be comprehensive. Further questions regarding the area of associate performance could be addressed. Considering that study has discovered the related psychological emotions (motivation, pride, and achievement), future 
research should involve deeper knowledge and analysis in this field to provide a clearer dimension of these emotions toward staff performance.

\section{References}

Abadi, F. E., Jalilvand, M. R., Sharif, M., Salimi, G. A., \& Khanzadeh, S. A. (2011). A study of influential factors on employees' motivation for participating in the in-service training courses based on modified expectancy theory. International Business and Management, 2(1), 157-169.

Ahmad, R., Solnet, D., \& Scott, N. (2010). Human resource practices system differentiation: A hotel industry study. Journal of Hospitality and Tourism Management, 17, 72-82. http://dx.doi.org/10.1375/jhtm.17.1.72

Bandura, A. (1997). Self-efficacy: The exercise of control. New York: Freeman.

Brymer, R. A. (1977). The Trainee's Perspective: What Every Management Trainee Would Like His Trainer to Know. Cornell Hotel and Restaurant Administration Quarterly, 17(4), 79-82. http://dx.doi.org/10.1177/001088047701700414

Chen, Y., \& Lau, H. (2002). Toward an understanding of the behavioral intention to use a groupware application. Journal of End User Computing, 14, 1-16.

Chiang, C. F., \& Jang, S. (2008). An expectancy theory model for hotel employee motivation. International Journal of Hospitality Management, 27(2), 313-322.

Chitiris, L. (1988). Herzberg's proposals and their applicability to the hotel industry. Journal of hospitality \& tourism research, 12, 67-79. http://dx.doi.org/10.1177/109634808801200106

Cohen, D., \& Crabtree, B. (2006). Qualitative Research Guidelines Project. Retrieved from http://www.qualres.org/HomeSemi-3629.html

Drever, E. (1995). Semi-structured interview in small-scale research: A teacher's guide. Scottish Council for Research in Education. Retrieved from http://www.eric.ed.gov/ERICWebPortal/recordDetail?accno=ED394990

Dul, J., \& Hak, T. (2008). Case study methodology in business research. Burlington: Elsevier.

Forrest, L. C. (1990). Training for the hospitality industry (2nd ed.). MI: Educational Institute of the American Hotel and Motel Association.

French, J. R., \& Raven, B. (1959). The bases of social power. Studies in social power, 150, 167.

Frone, M. R. (2003). Work-family balance. In J. C. Quick, \& L. E. Tetrick (Eds.), Handbook of occupational health psychology (pp. 143-162). Washington, DC: American Psychological Association. http://dx.doi.org/10.1037/10474-007

Greenhaus, J. H., \& Beutell, N. J. (1985). Sources of conflict between work and family roles. Academy of Management Journal, 10, 76-88.

Hecht, T. D., \& McCarthy, J. M. (2010). Coping with employee, family, and student roles: Evidence of dispositional conflict and facilitation tendencies. Journal of Applied Psychology, 95(4), 631-647. http://dx.doi.org/10.1037/a0019065

Herzberg, F. (1966). Work and the nature of man. Cleveland: World Publishing Company.

Herzberg, F., Mausner, B., \& Snyderman, B. (1959). The motivation to work. New York: Wiley.

Hull, C. L. (1943). Principles of behaviour. New York: Appleton-Century-Crofts.

Karatepe, O. M., \& Uludag, O. (2007). Conflict, exhaustion, and motivation: A study of frontline employees in Northern Cyprus hotels. International Journal of Hospitality Management, 26, 645-665. http://dx.doi.org/10.1016/j.ijhm.2006.05.006

Lewis, M. (1997). The self in self-conscious emotions. In J. G. Snodgrass, \& R. L. Thompson (Eds.), Self across psychology: Self-recognition, self-awareness, and the self-concept (pp. 119-142). New York: New York Academy of Sciences.

Locke, E. A., \& Latham, G. P. (1990). A theory of goal setting and task performance. Englewood Cliffs, NJ: Prentice-Hall.

Lundberg, C., Gudmundson, A., \& Andersson, T. D. (2009). Herzberg's Two-Factor Theory of work motivation tested empirically on seasonal workers in hospitality and tourism. Tourism Management, 30, 890-899. http://dx.doi.org/10.1016/j.tourman.2008.12.003 
Maslow, A. H. (1943). A theory of human motivation. Psychological Review, 50(4), 370-396. http://dx.doi.org/10.1037/h0054346

McClelland, D. C. (1971). Assessing human motivation. New York: General Learning Press.

Meyer, J. P., Becker, T. E., \& Vangdenberghe, C. (2004). Employee commitment and motivation: A conceptual analysis and integrative model. Journal of Applied Psychology, 89(6), 991-1007. http://dx.doi.org/10.1037/0021-9010.89.6.991

Parsons, E., \& Broadbride, A. (2006). Job motivation and satisfaction: unpacking the key factors for charity shop managers. Journal of Retailing and Consumer Services, 13(2), 121-131. http://dx.doi.org/10.1016/j.jretconser.2005.08.013

Perry, C. (2001). Case research in marketing. The Marketing Review, 1, 303-323. http://dx.doi.org/10.1362/1469347002530790

Pinder, C. C. (1998). Motivation in work organizations. Upper Saddle River. NJ: Prentice Hall.

Powell, V. (2009). What effect do formalized human resource procedures such as contracts and appraisals have on employee motivation in the hospitality industry? [Unpublished Paper] Chester Business School.

Rowe, A. K., de Savigny, D., Lanata, C. F., \& Victora, C. G. (2005). How can we achieve and maintain high-quality performance of health workers in low-resource settings? The Lancet, 366(9490), 1026-1035. http://dx.doi.org/10.1016/S0140-6736(05)67028-6

Sledge, S., Miles, A. K., \& Coppage, S. (2008). What role does culture play? A look at motivation and job satisfaction among hotel workers in Brazil. The International Journal of Human Resource Management, 19(9), 1667-1682. http://dx.doi.org/10.1080/09585190802295157

Steers, R. M., Mowday, R. T., \& Shapiro, D. L. (2004). The future of work motivation theory. Academy of Management Review, 29(3), 379-387.

Tangney, J. P. (1999). The self-conscious emotions: Shame, guilt, embarrassment and pride. In T. Dalgleish, \& M. J. Power (Eds.), Handbook of cognition and emotion (pp. 541-568). New York: Wiley.

Thorndike, E. L. (1911). Animal intelligence. New York: Macmillan.

Tolman, E. C. (1959). Principle of purposive behaviour. In S. Koch (Ed.), Psychology: A study of science, 2, 239-261. New York: McGraw-Hill.

Vroom, V. H. (1964). Work and motivation. California: Wiley.

Weick, K. E., Bougon, M. G., \& Maruyama, G. (1976). The equity context. Organizational Behavior and Human Performance, 15, 32-65. http://dx.doi.org/10.1016/0030-5073(76)90028-3

Williams, L. A., \& DeSteno, D. (2008). Pride and perseverance: The motivational role of pride. Journal of personality and social psychology, 94(6), 1007. http://dx.doi.org/10.1037/0022-3514.94.6.1007

Wong, S., Siu, V., \& Tsang, N. (1999). The impact of demographic factors on Hong Kong hotel employees' choice of job-related motivators. International Journal of Contemporary Hospitality Management, 11(5), 230-241. http://dx.doi.org/10.1108/09596119910272766

Young-Thelin, L., \& Bolu, K. (2012). A case study of human resource practices in small hotels in Sweden. Journal of Human Resources in Hospitality \& Tourism, 11(4), 327-353. http://dx.doi.org/10.1080/15332845.2012.690683

\section{Copyrights}

Copyright for this article is retained by the author(s), with first publication rights granted to the journal.

This is an open-access article distributed under the terms and conditions of the Creative Commons Attribution license (http://creativecommons.org/licenses/by/3.0/). 